\title{
Organocatalytic redox isomerization of electron-deficient allylic alcohols: Synthesis of 1,4-ketoaldehydes
}

\author{
Keshab Mondal, Buddhadeb Mondal and Subhas Chandra Pan` \\ Department of Chemistry, Indian Institute of Technology Guwahati, Assam, 781039
}

\section{Supporting Information}

1. Optimization table...................................... 2

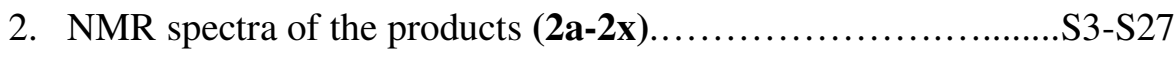

3. NMR spectra of the deuterium incorporation experiment........S28 
Optimization table (solvent screening):

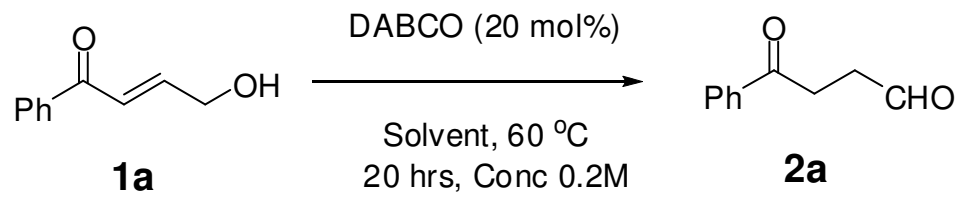

\begin{tabular}{|c|c|c|}
\hline No. $^{\left[{ }^{[}\right]}$ & Solvent & Yield (\%) $^{[\mathrm{b}]}$ \\
\hline 1 & 1,2 dichloroethane & 78 \\
\hline 2 & Toluene & 75 \\
\hline 3 & $\mathrm{CH}_{3} \mathrm{CN}$ & 63 \\
\hline 4 & THF & 70 \\
\hline 5 & Dioxane & 82 \\
\hline 6 & DMF & $\mathbf{9 3}$ \\
\hline 7 & DMSO & \\
\hline
\end{tabular}

${ }^{\left[{ }^{a}\right]}$ All reactions were carried out with compound 1a $(0.2 \mathrm{mmol})$ in $1 \mathrm{~mL}$ solvent. $\left.{ }^{b}\right]$ Isolated yield after silica gel column chromatography.

Catalyst and temperature screening:<smiles>O=C(/C=C/CO)c1ccccc1</smiles>

$1 \mathrm{a}$

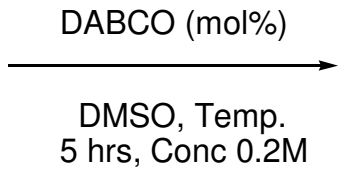

$5 \mathrm{hrs}$, Conc $0.2 \mathrm{M}$<smiles>O=CCCC(=O)c1ccccc1</smiles>

\begin{tabular}{|c|c|c|c|}
\hline No. & Catalyst (mol \%) & Temp $\left({ }^{\mathbf{0}} \mathbf{C}\right)$ & Yield (\%) \\
\hline $\mathbf{1}$ & DABCO (20) & $\mathbf{9 0}$ & $\mathbf{9 5}$ \\
\hline 2 & DABCO (10) & 90 & 89 \\
\hline 3 & DABCO (20) & 120 & 67 \\
\hline 4 & No Catalyst & 90 & 0 \\
\hline
\end{tabular}

${ }^{[a]}$ All reactions were carried out with compound $\mathbf{1 a}(0.2 \mathrm{mmol})$ in $1 \mathrm{~mL}$ solvent. ${ }^{[b]}$ Isolated yield after silica gel column chromatography. 
NMR spectra of the products:
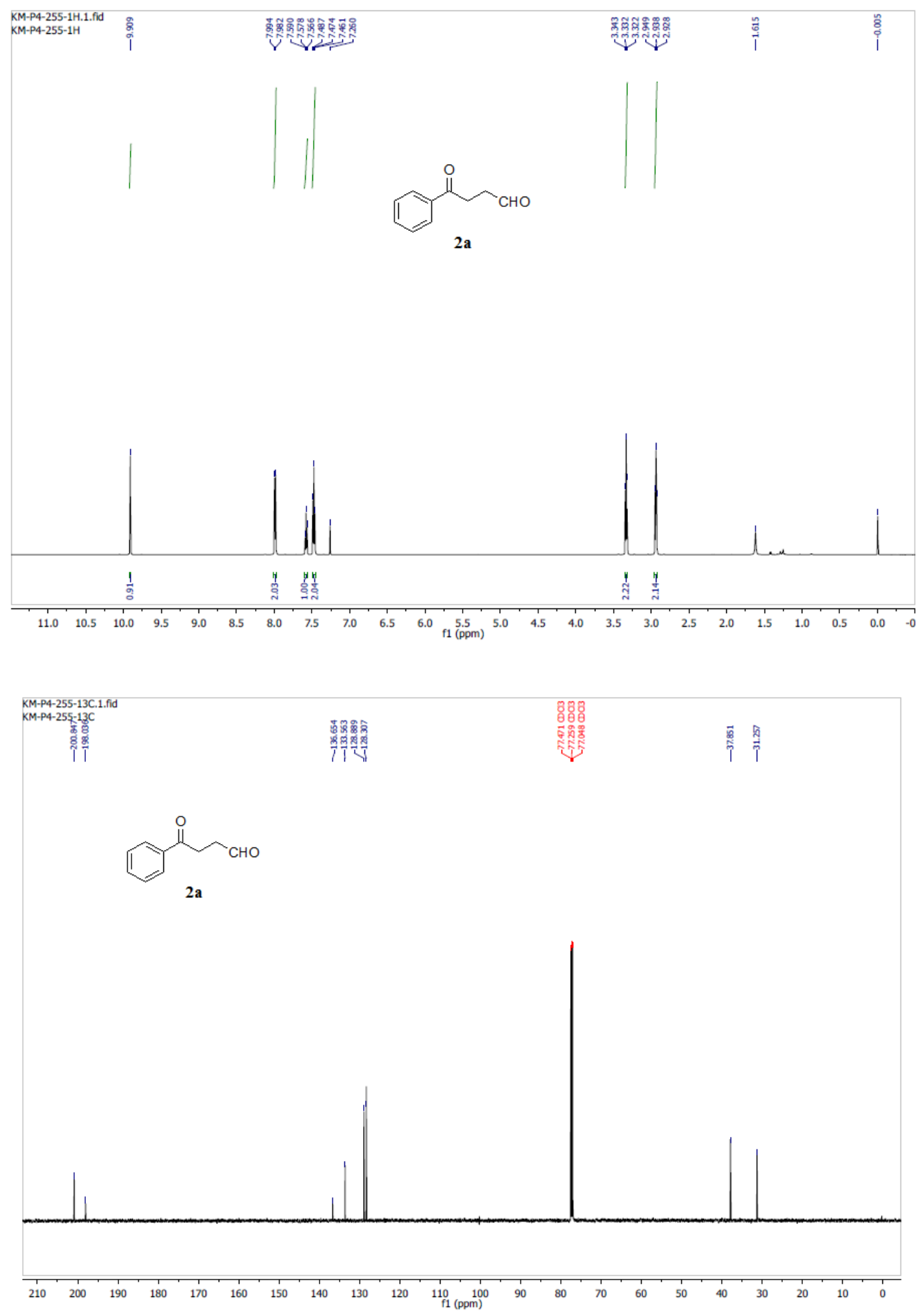

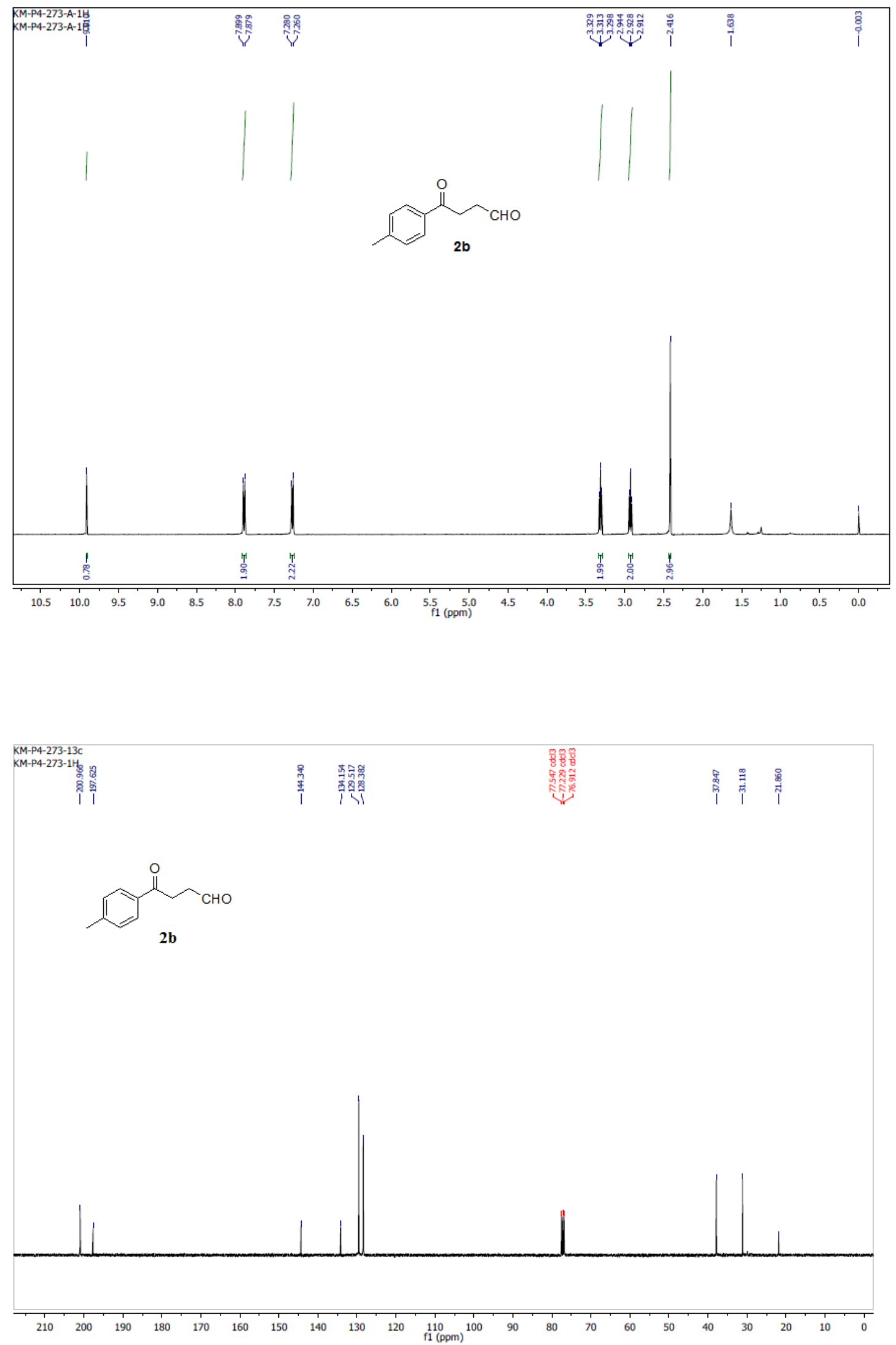

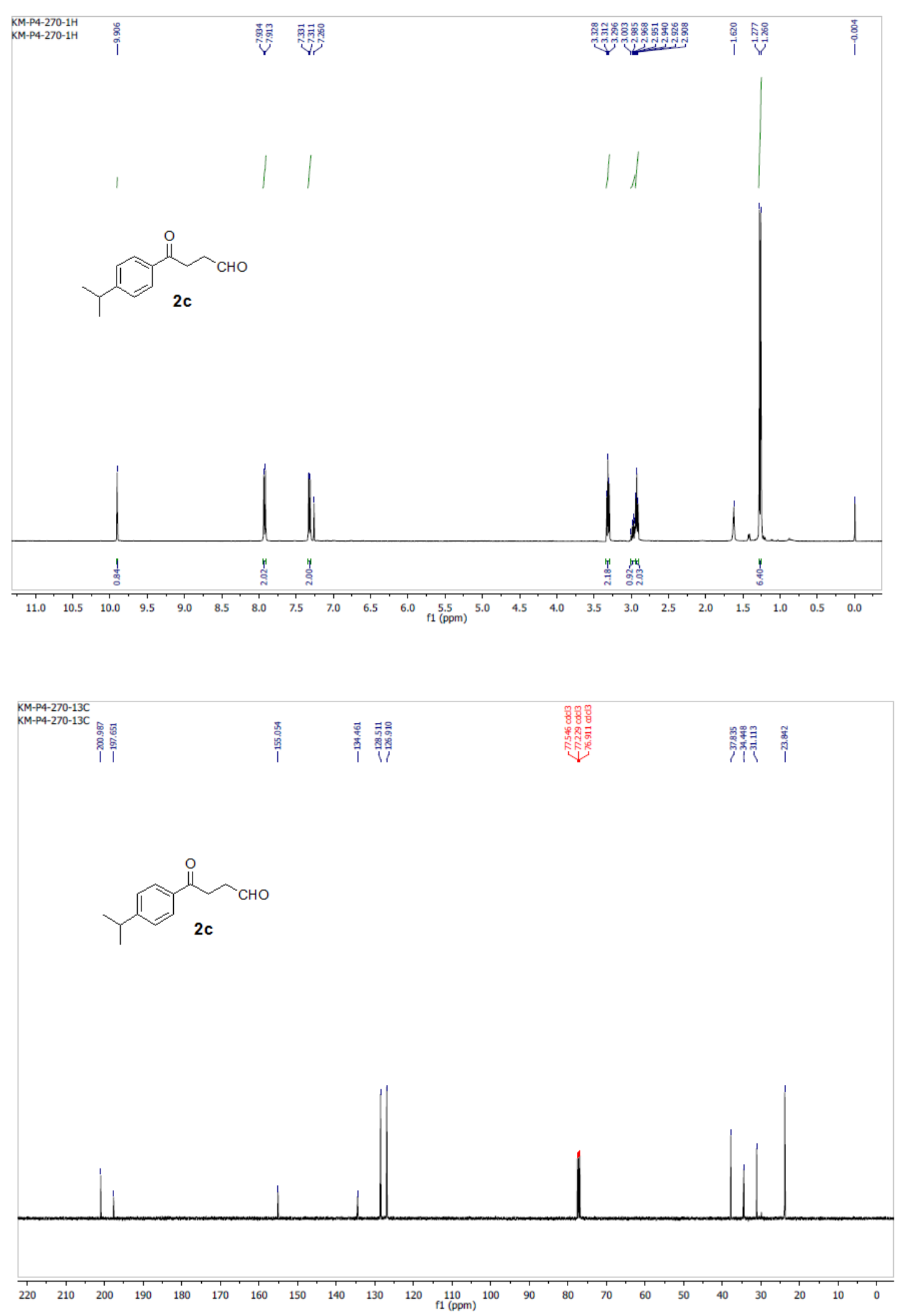

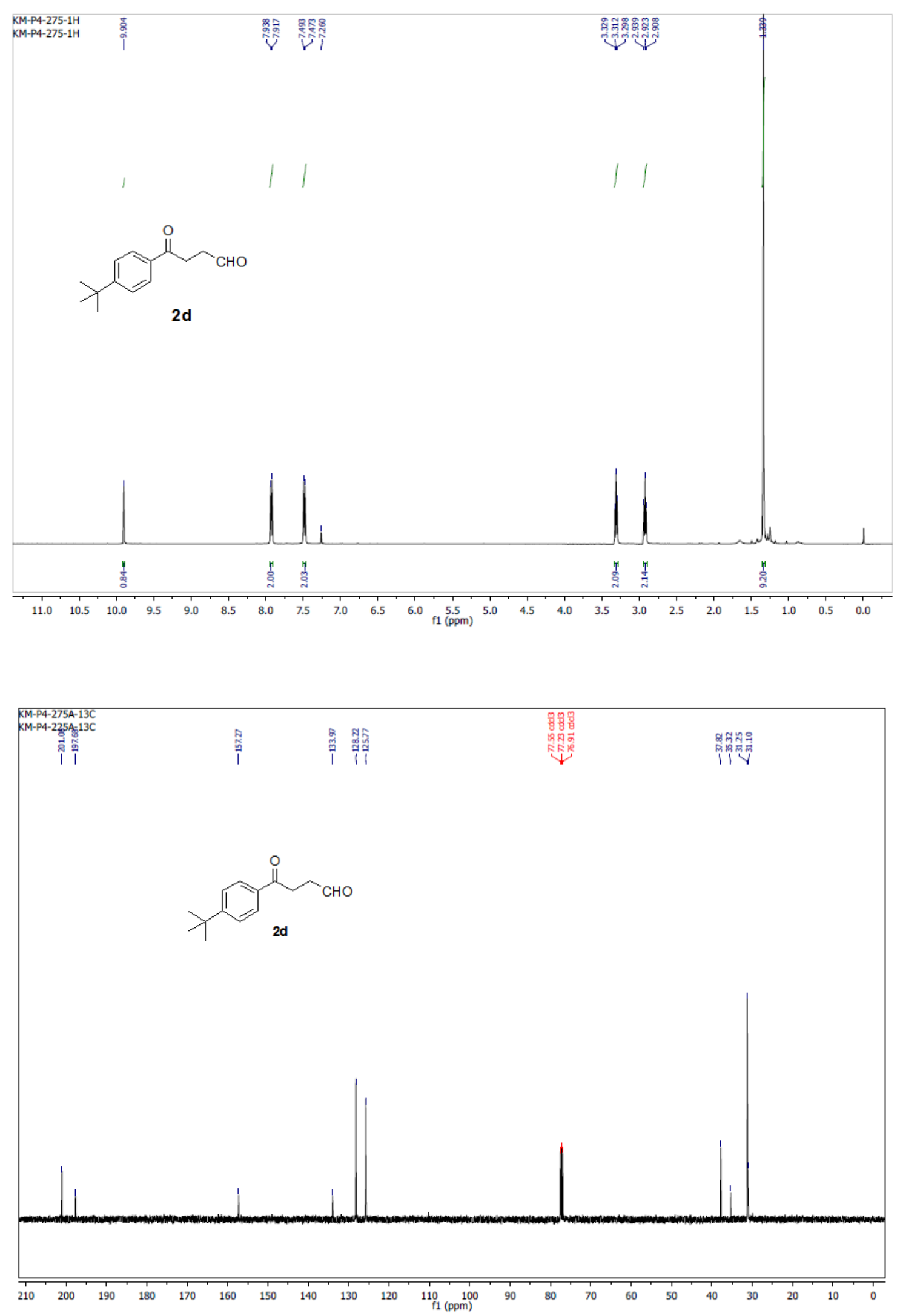

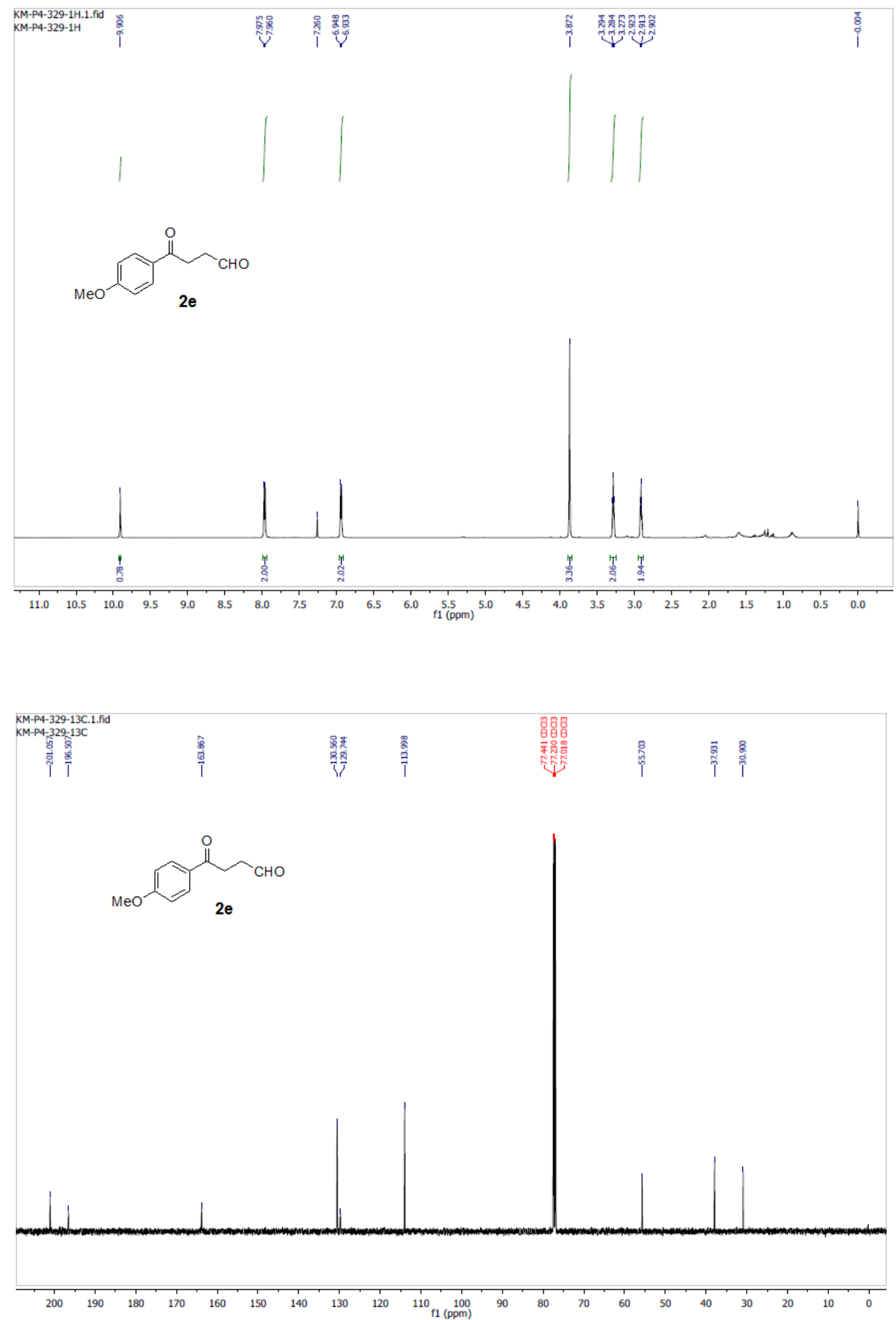

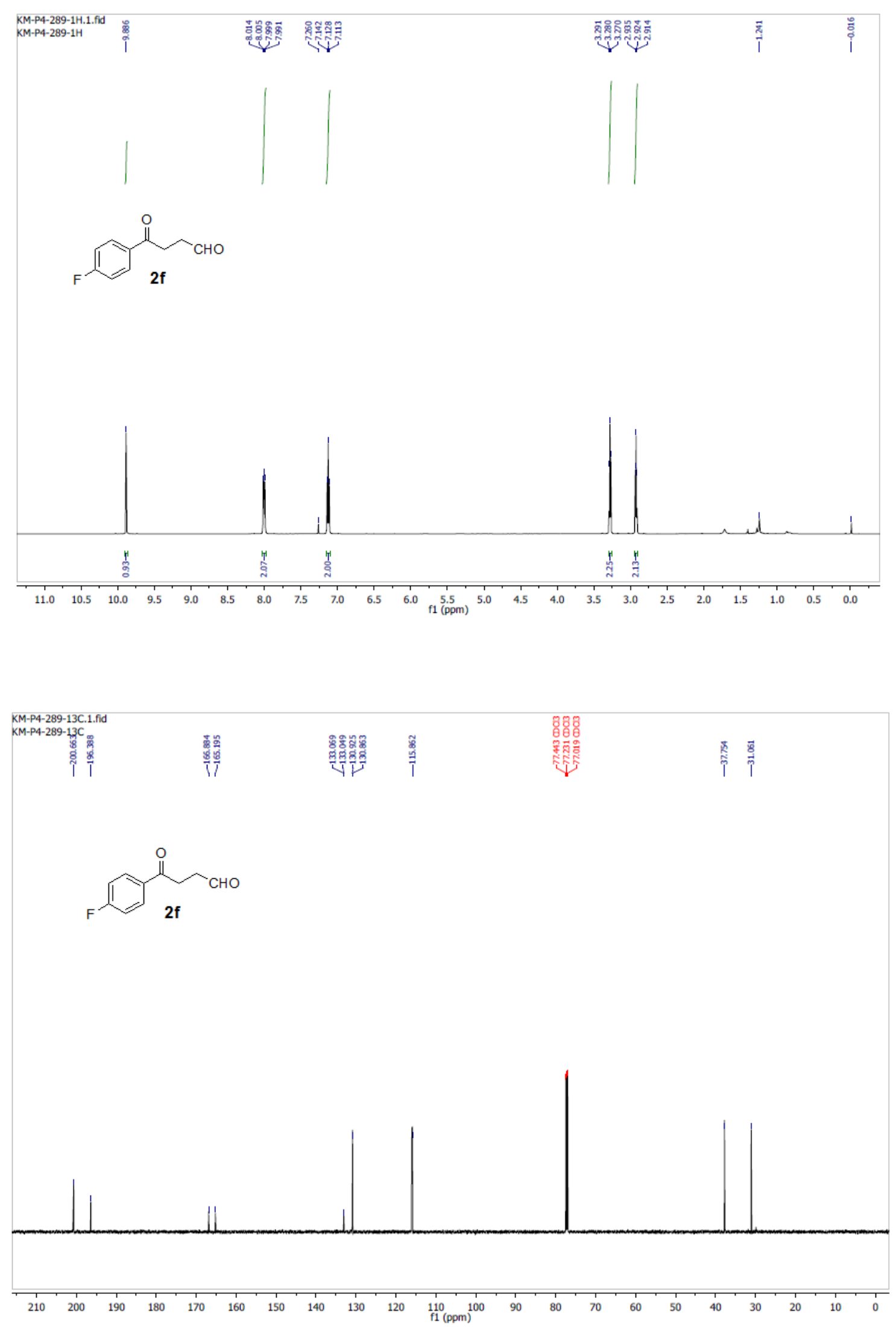

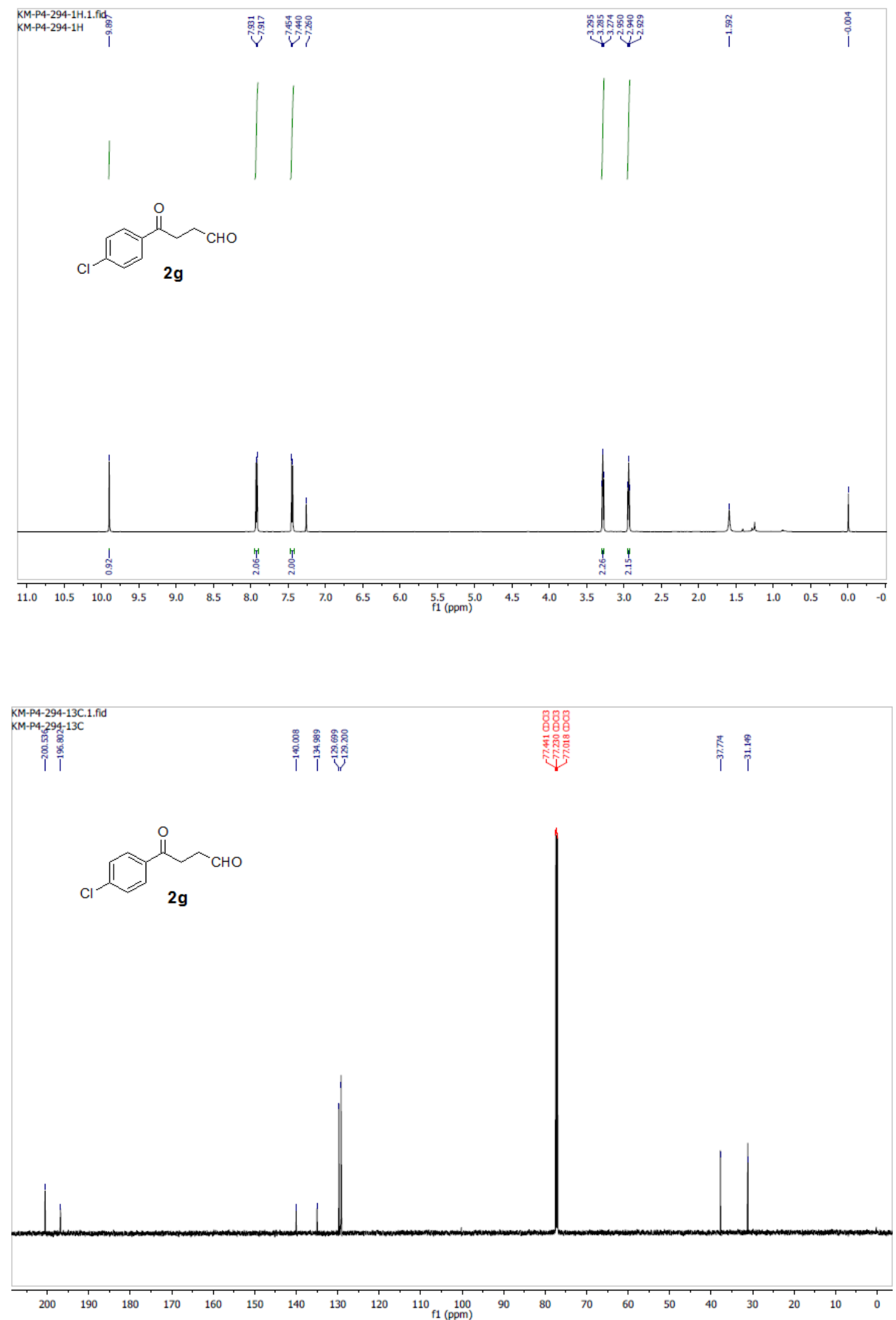

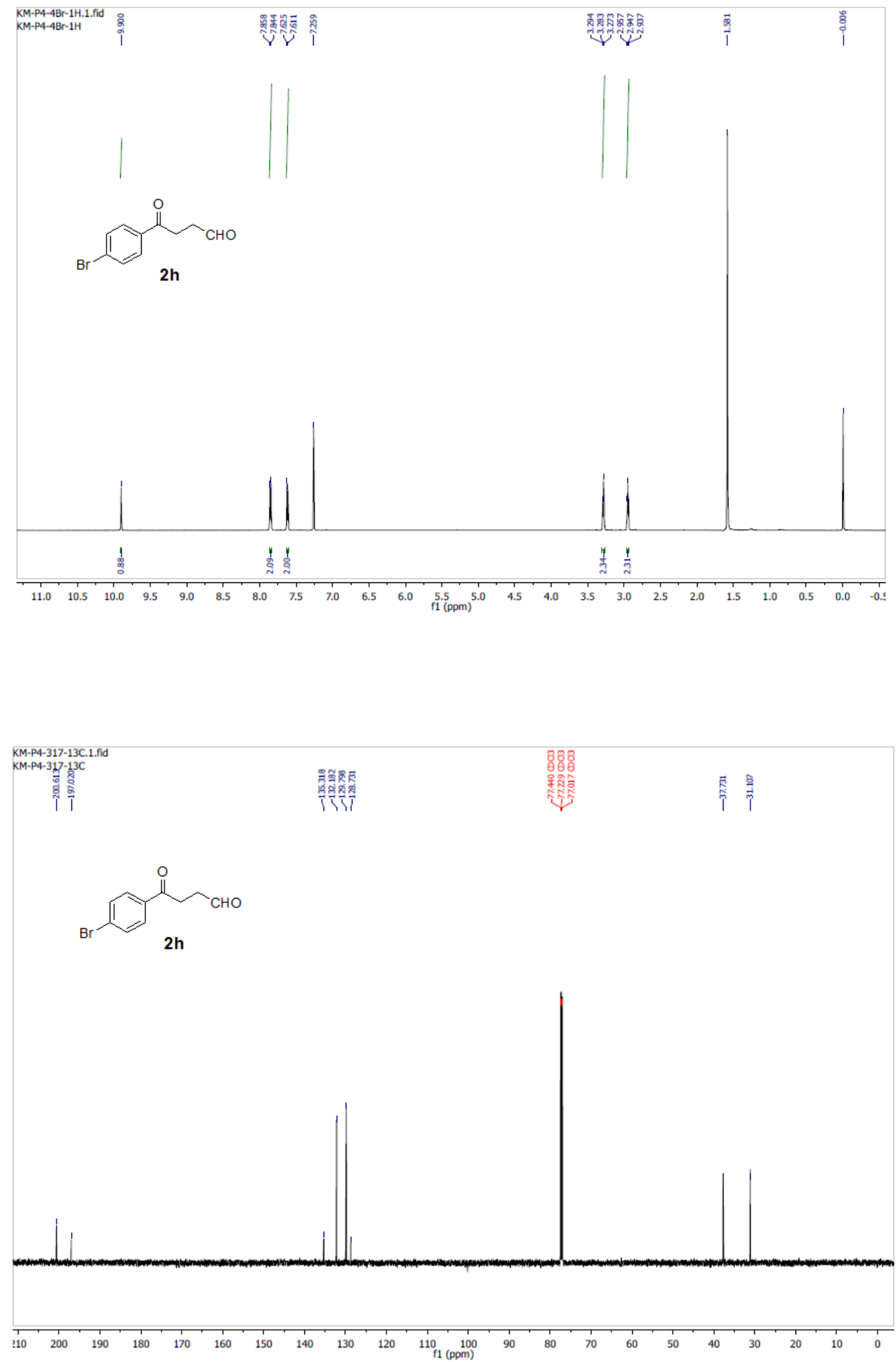

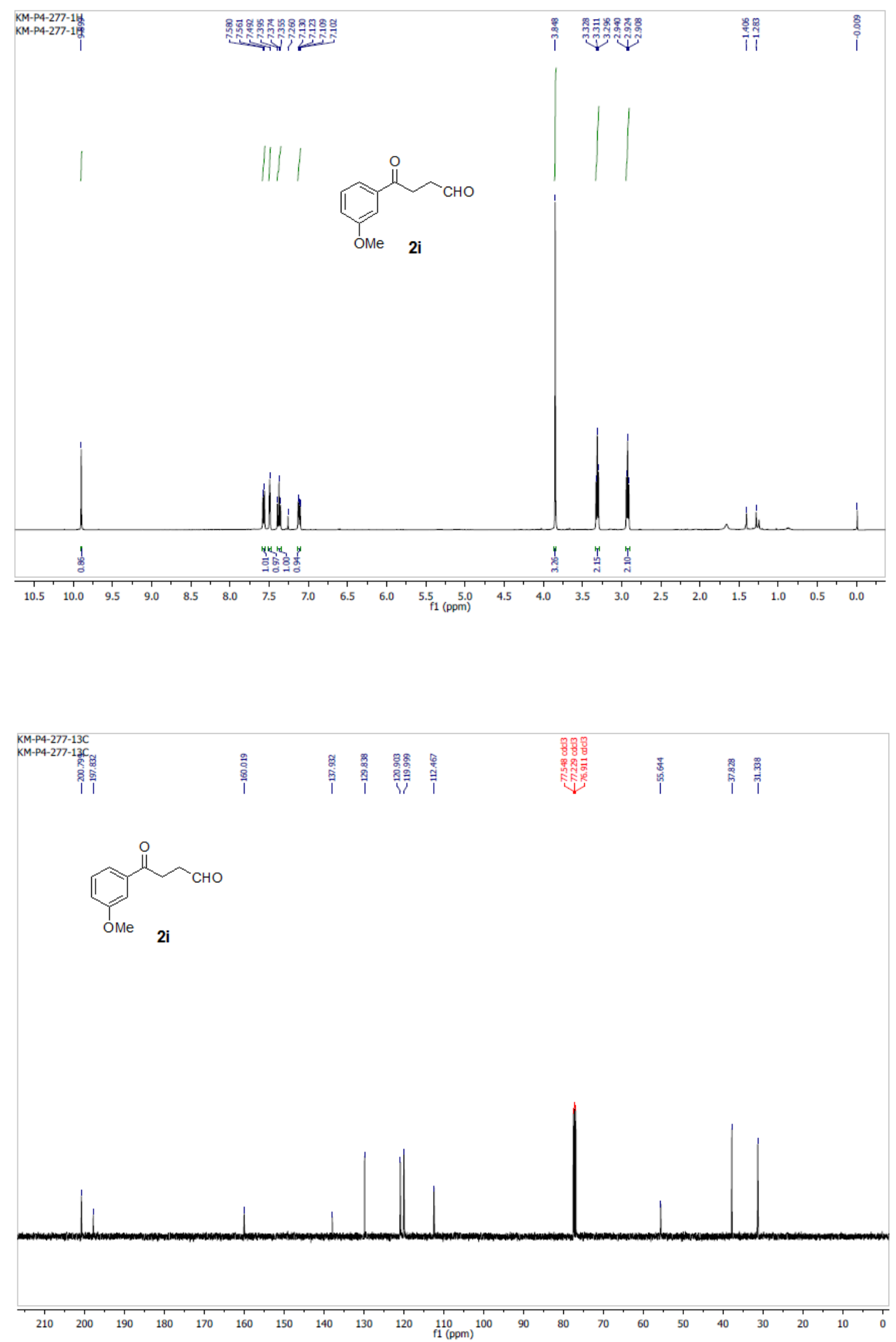

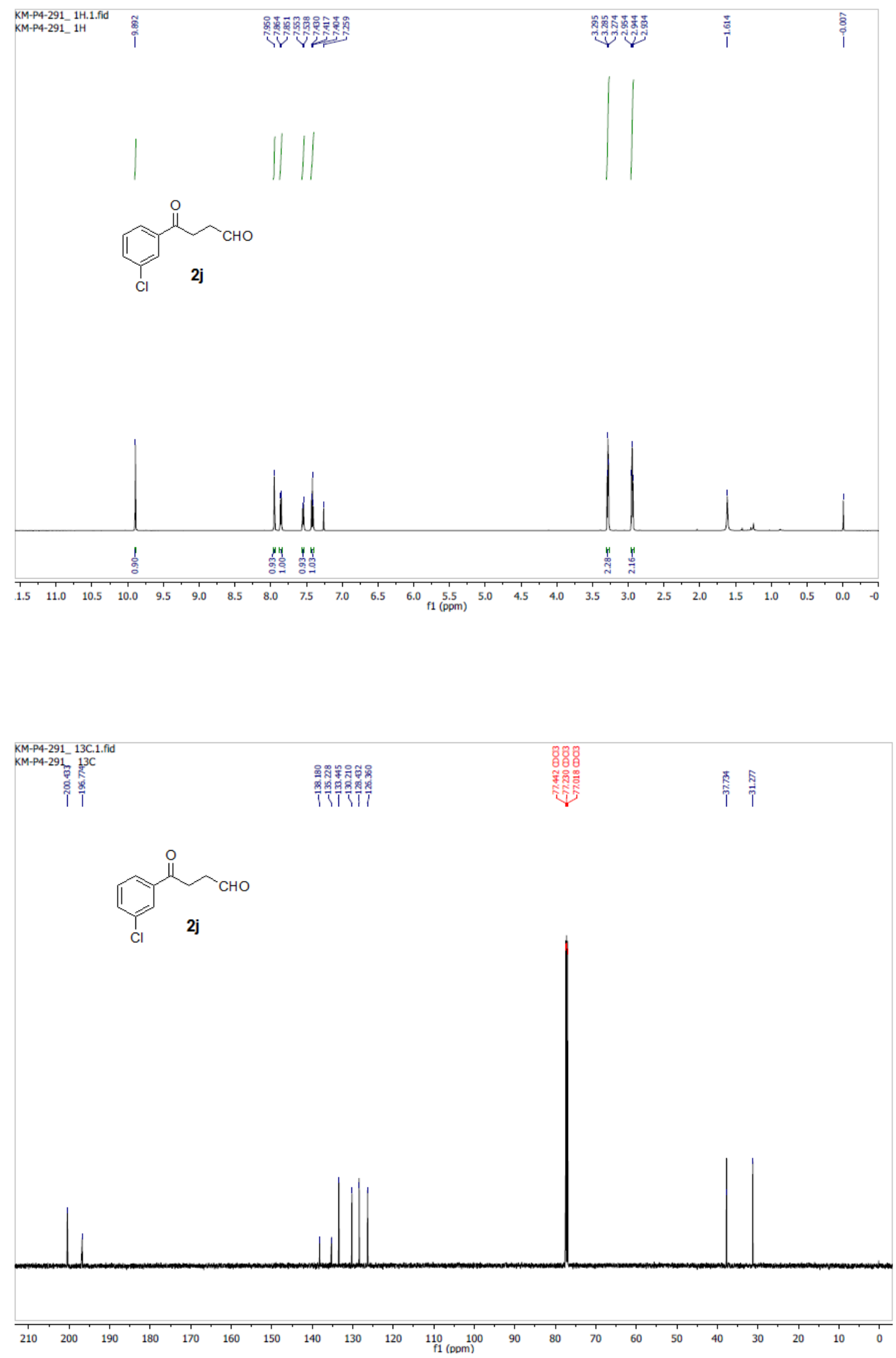

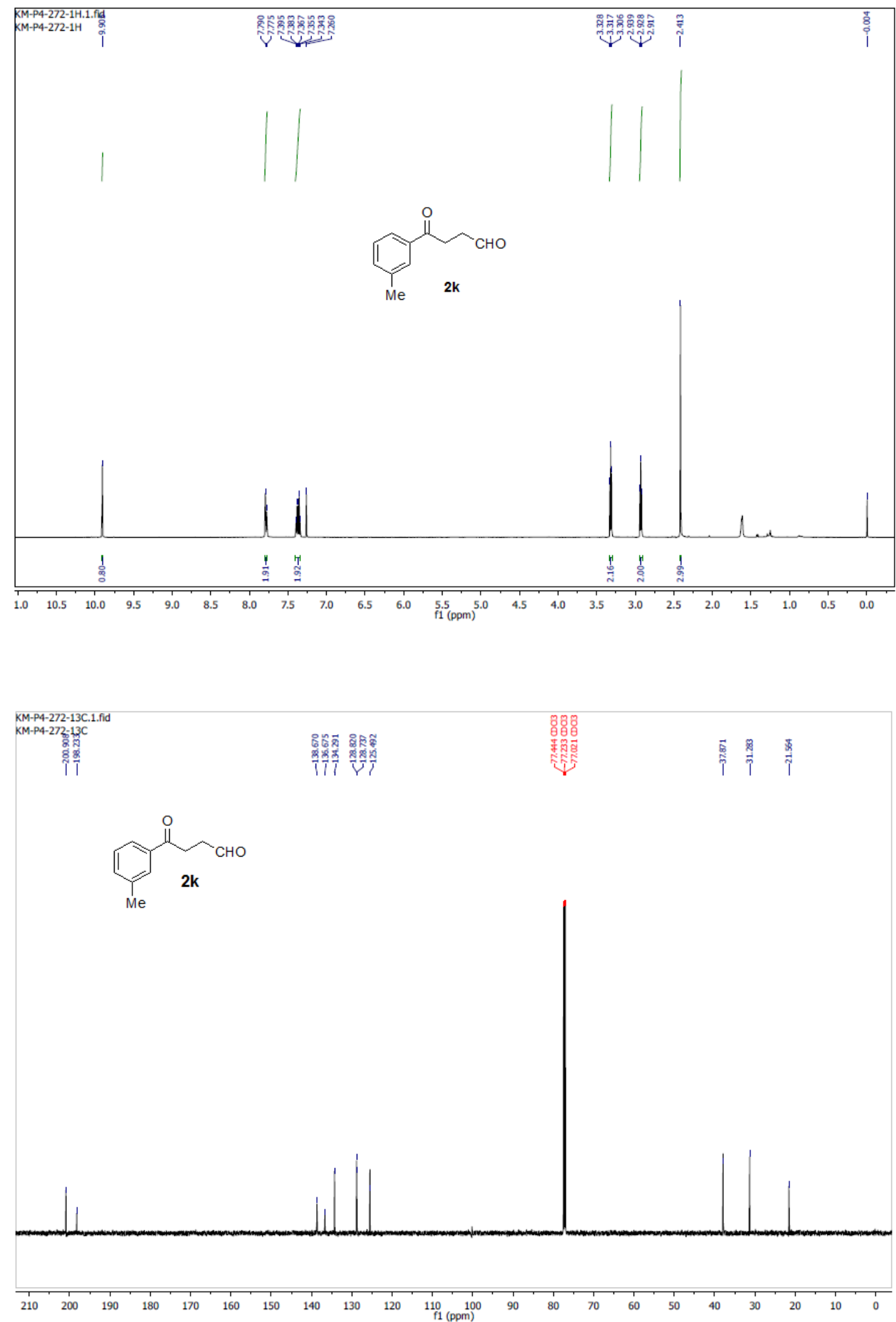

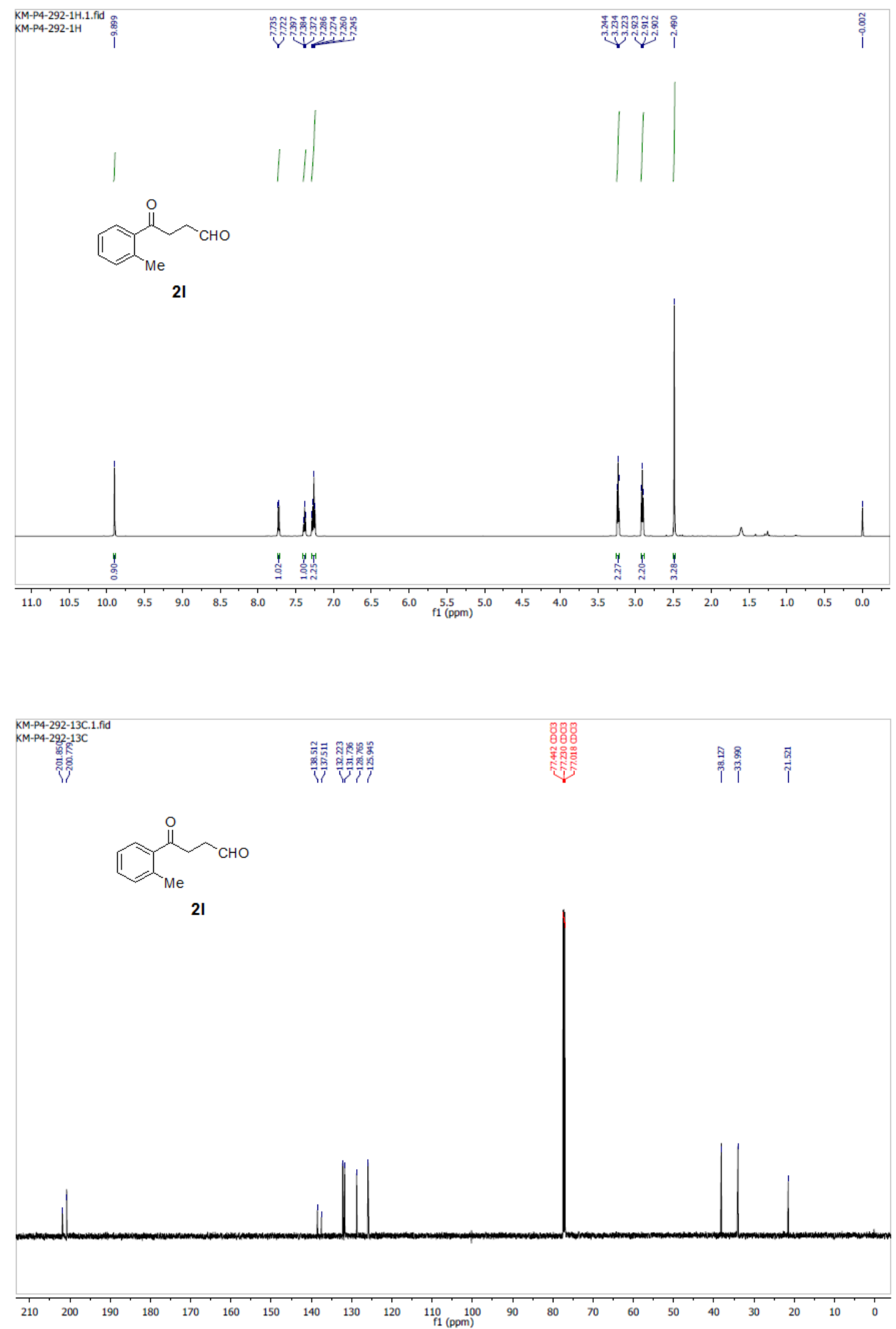

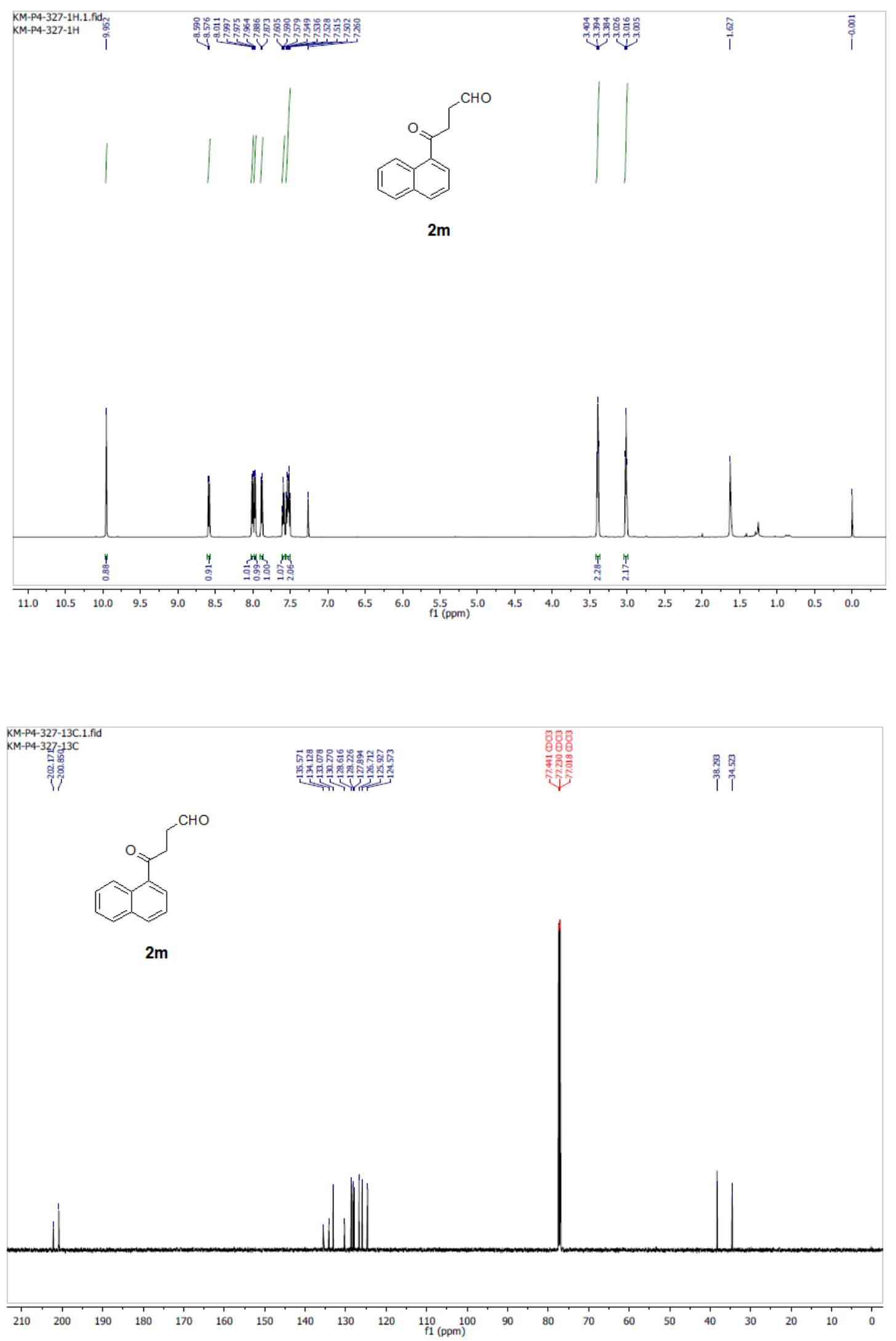

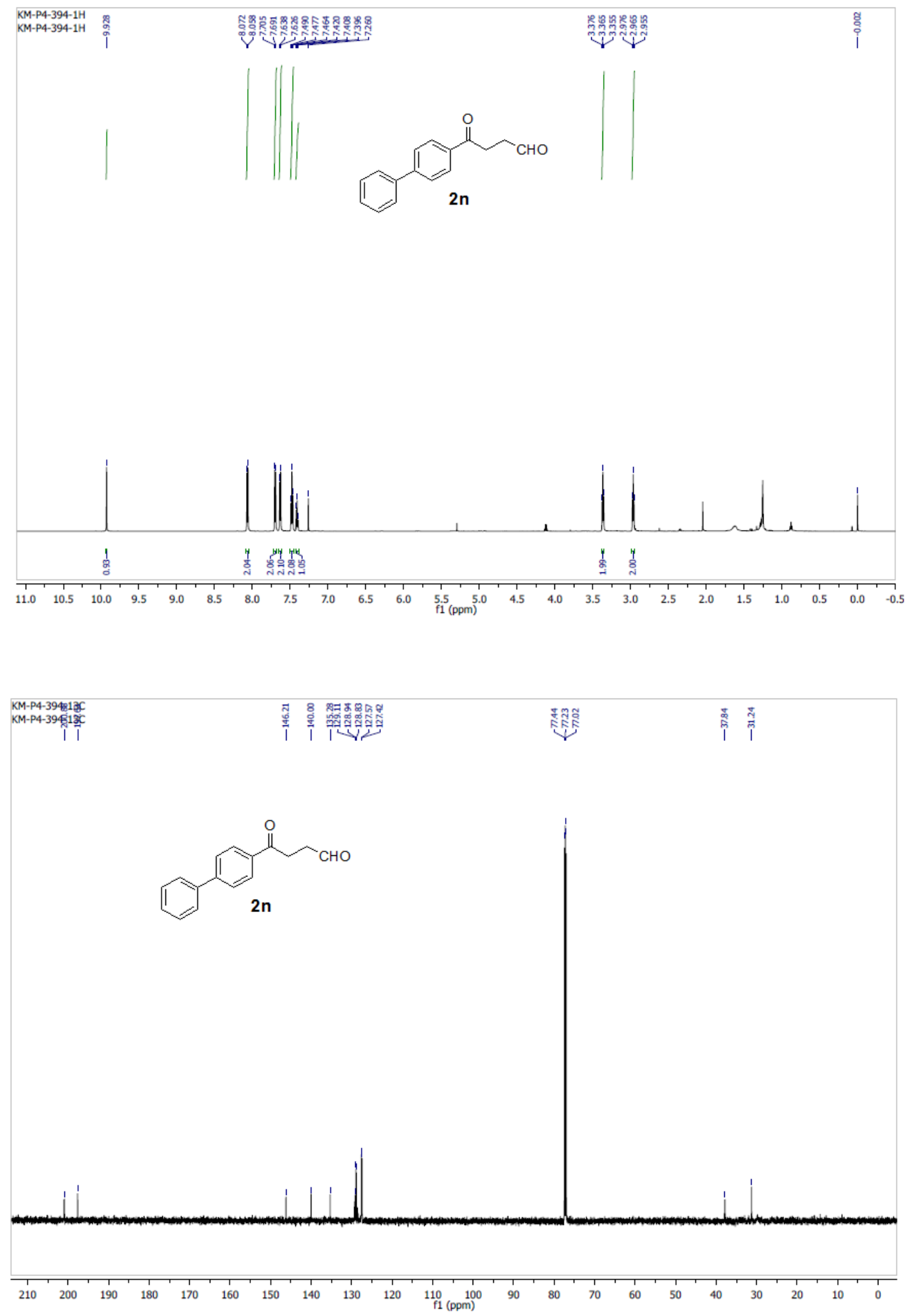

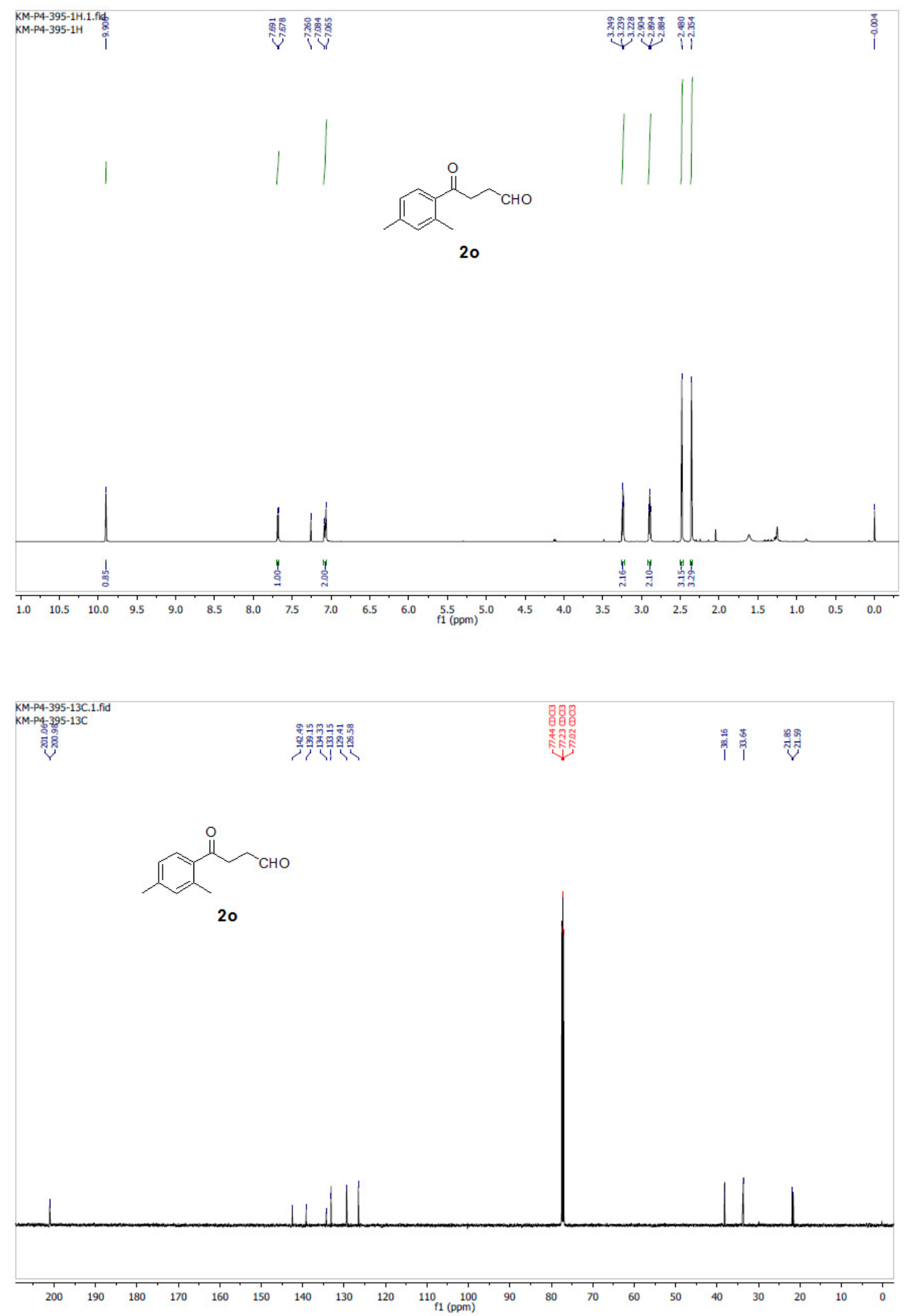

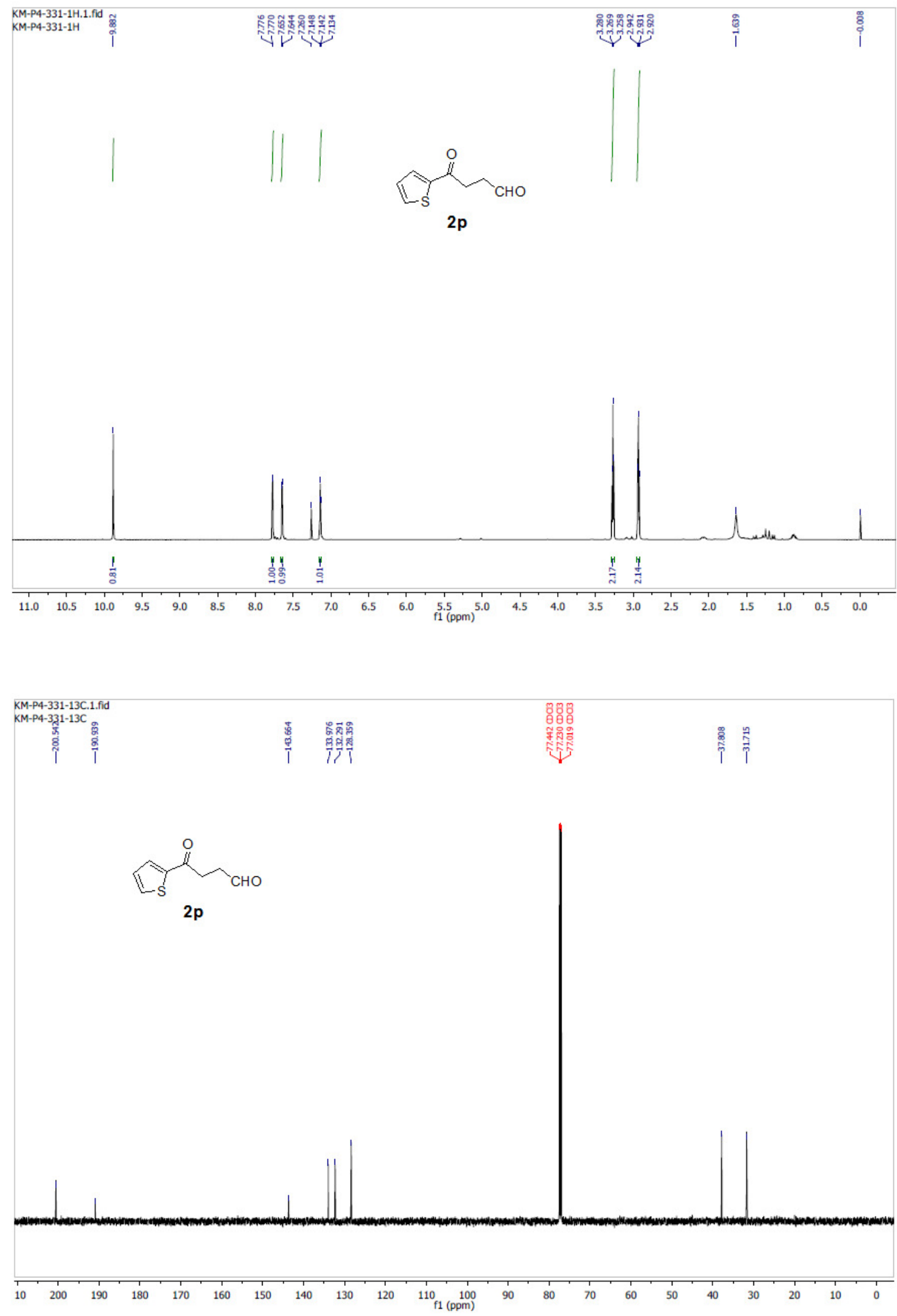

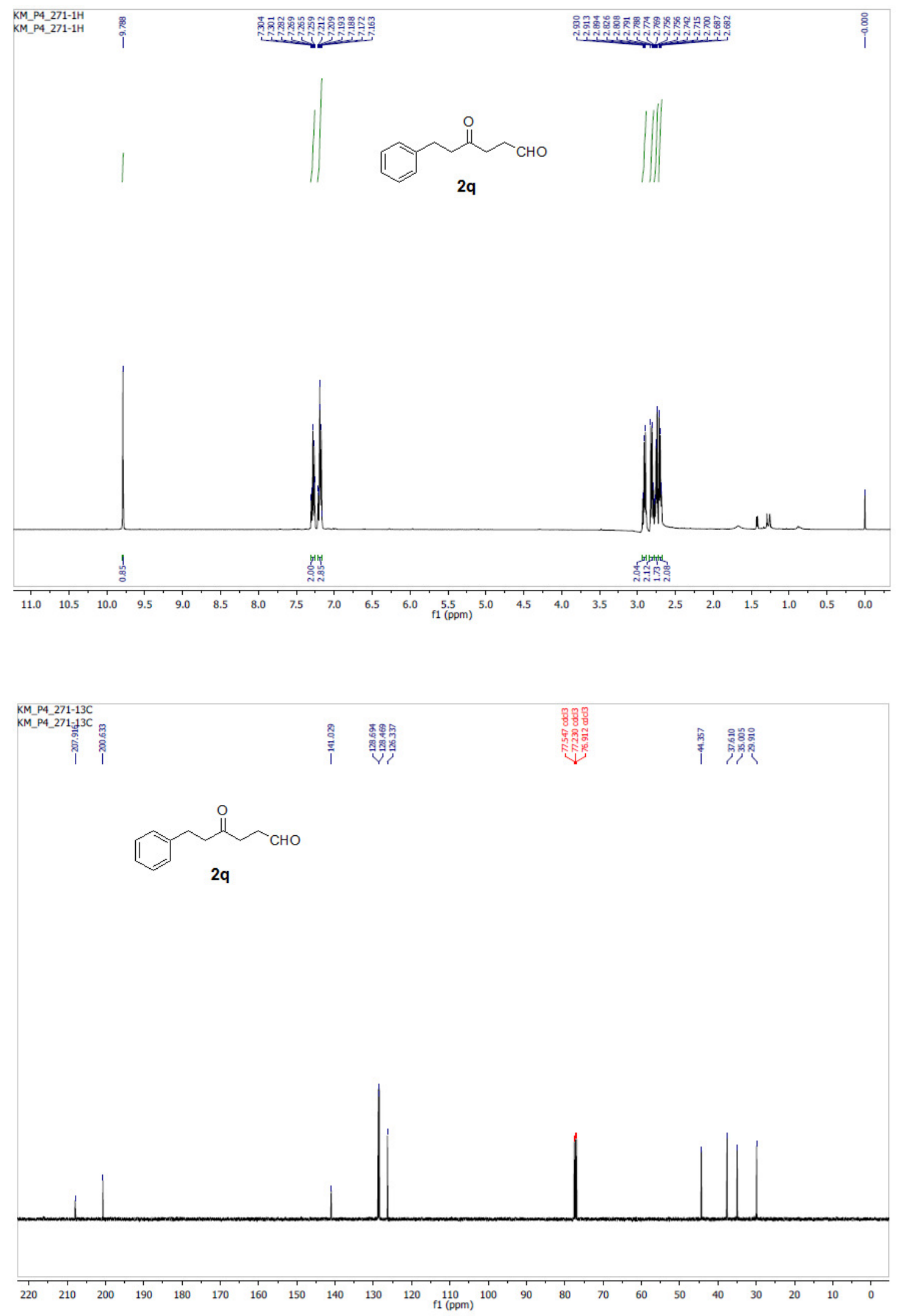

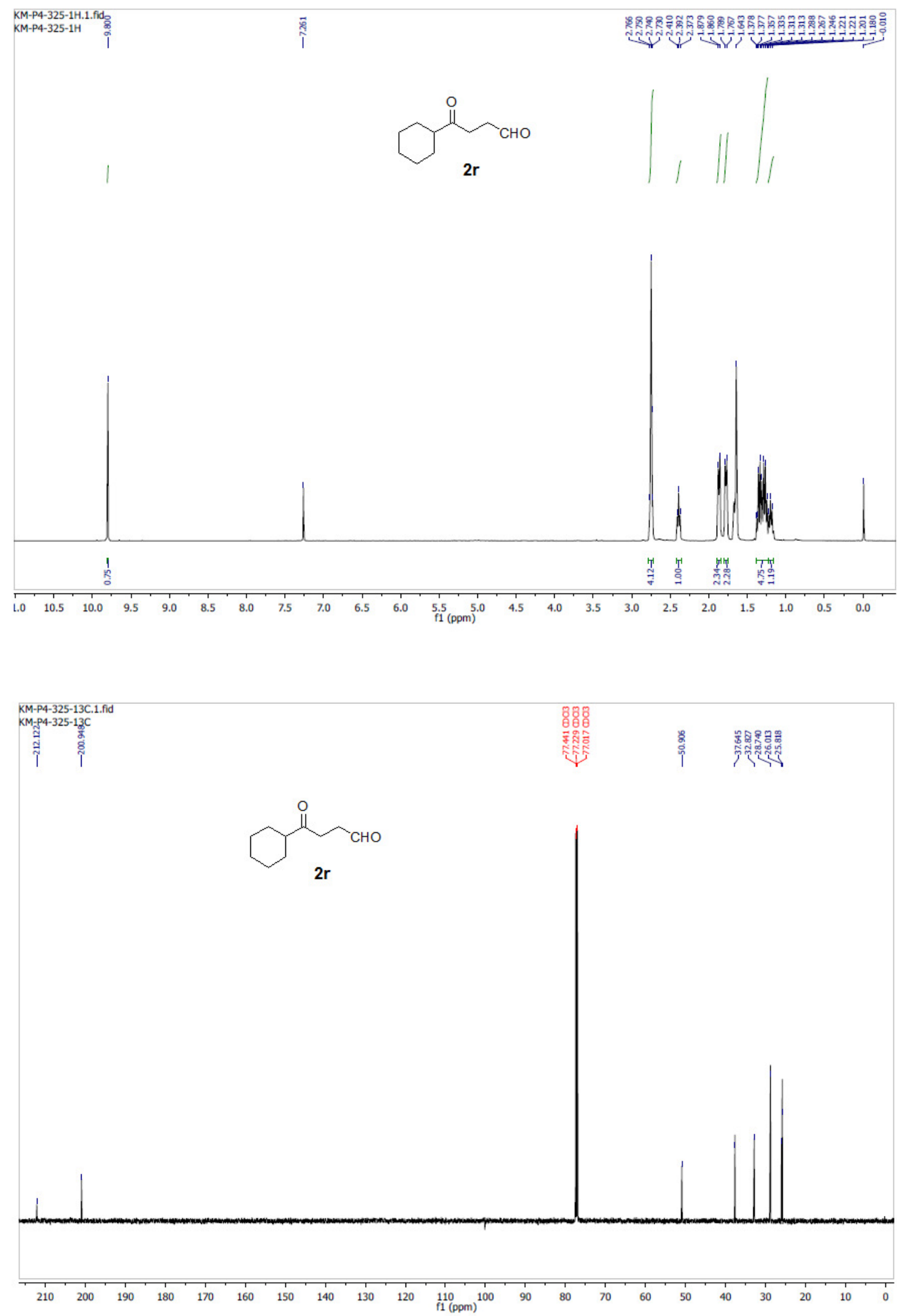

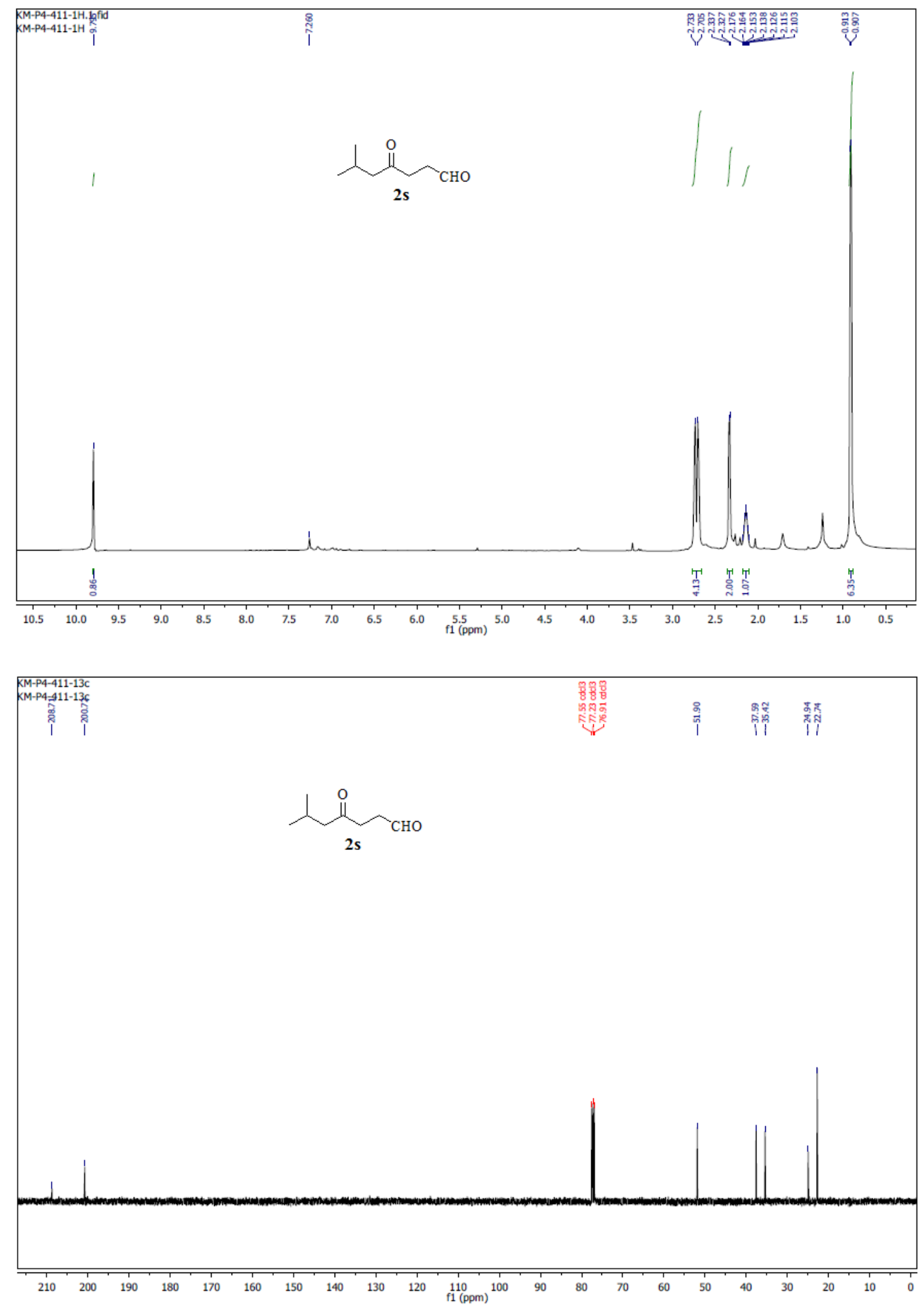

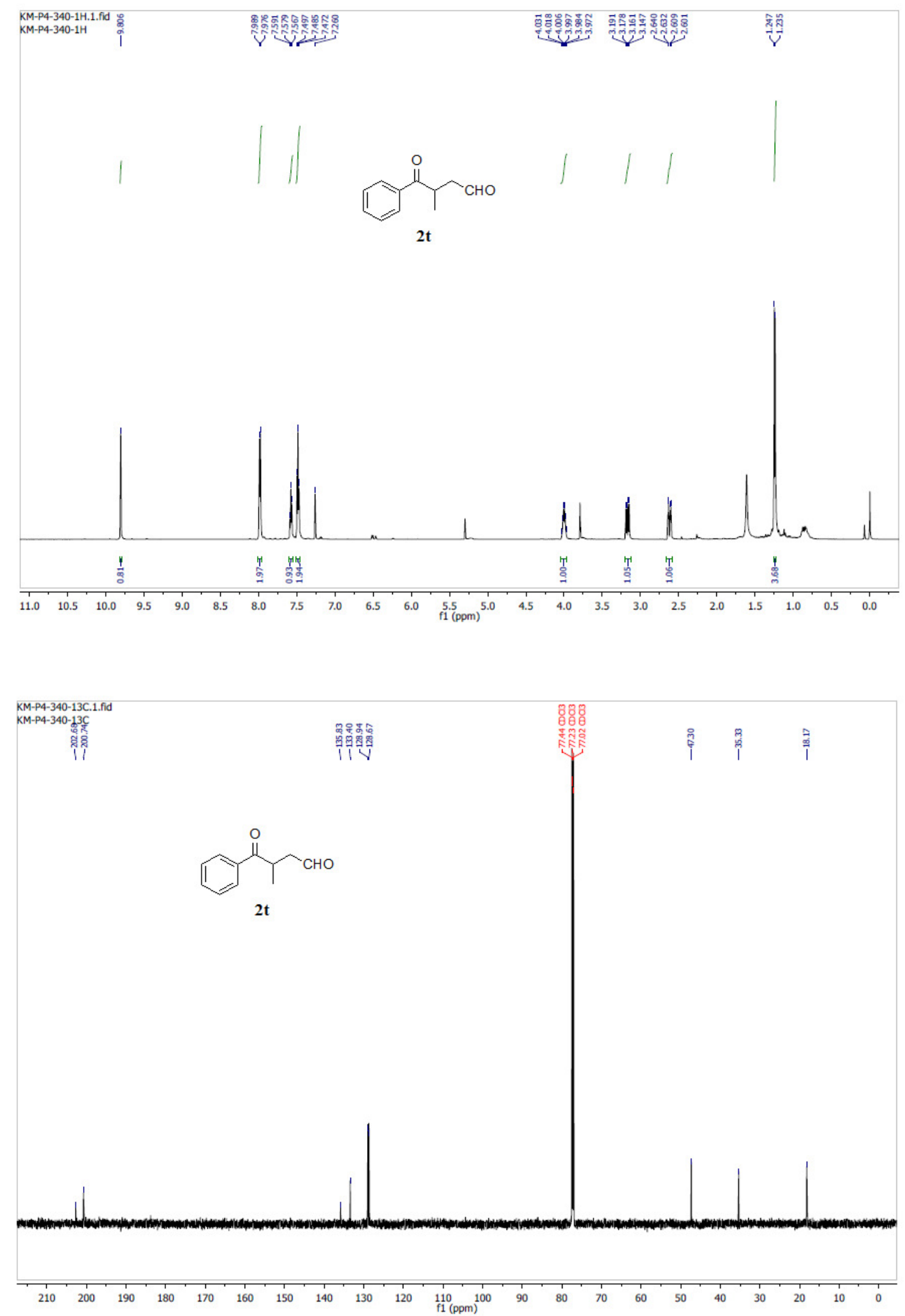

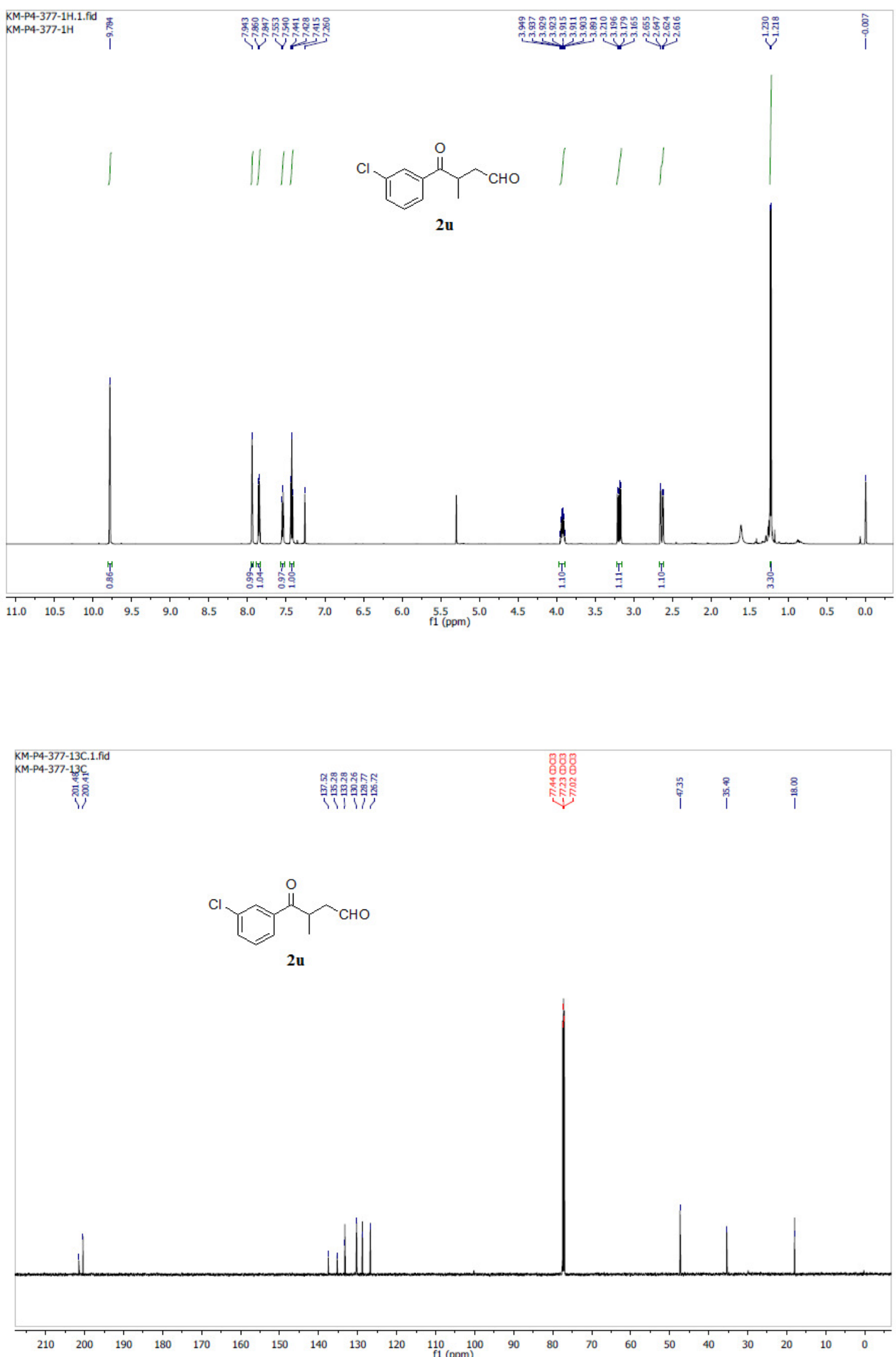

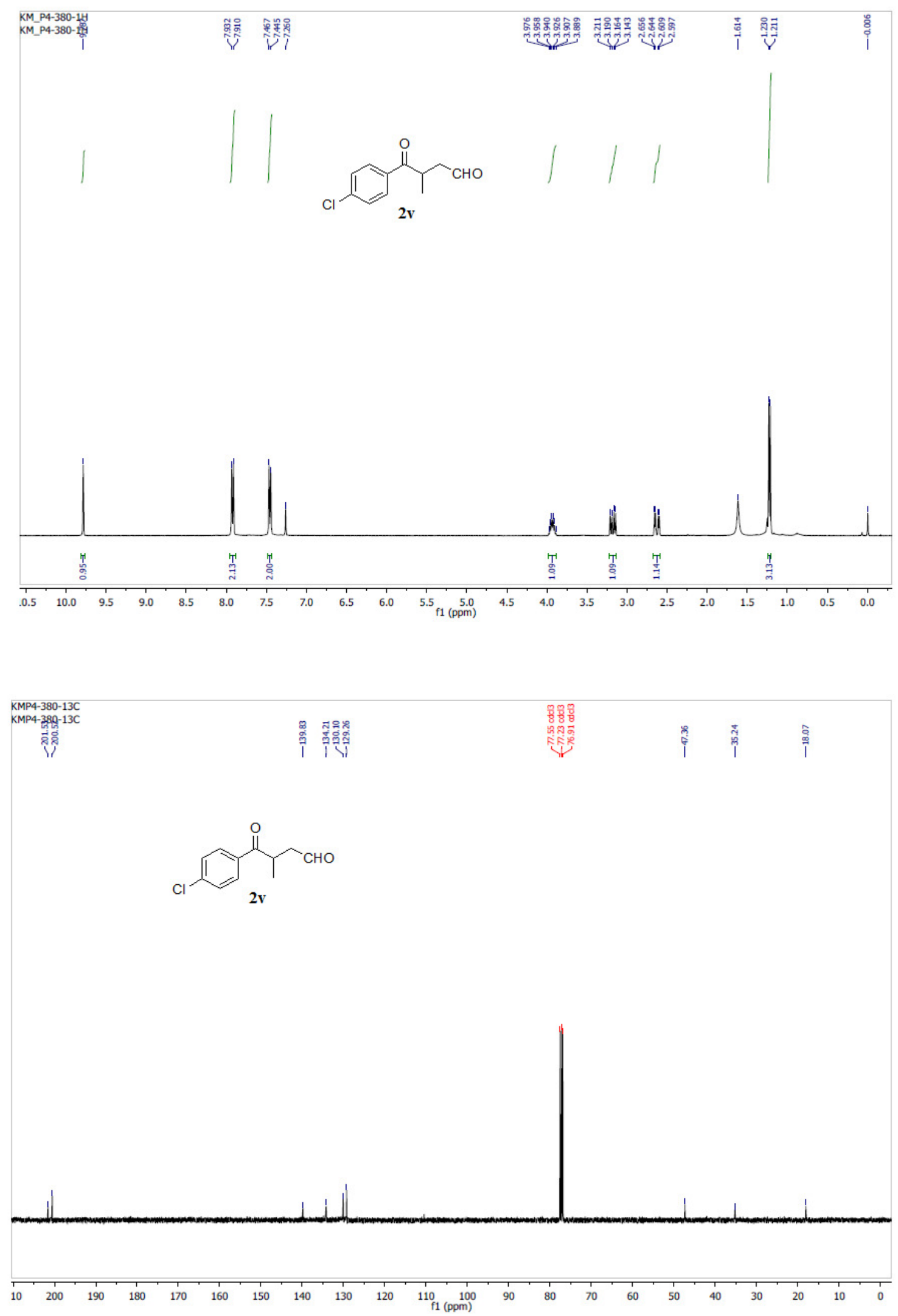

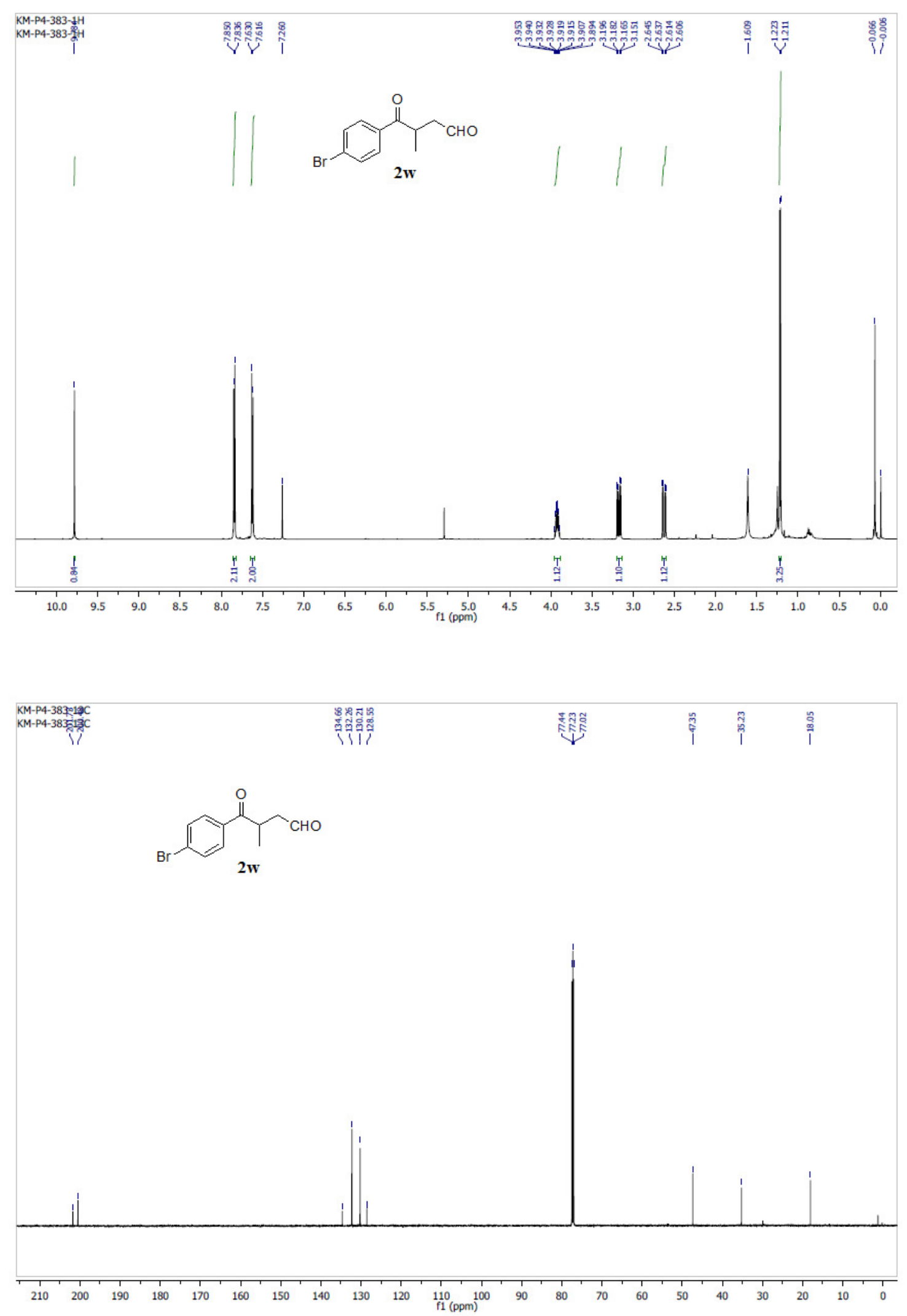

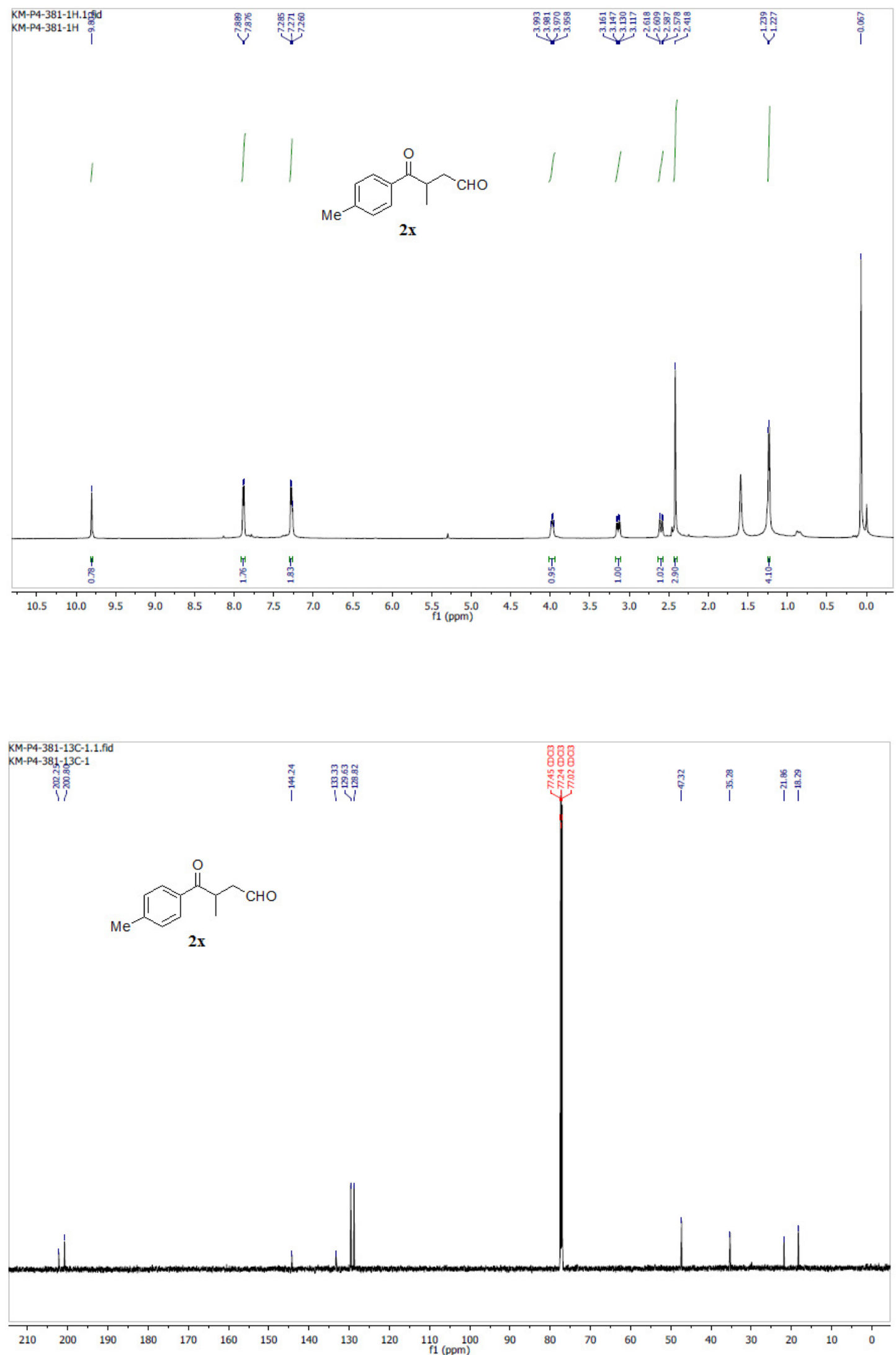

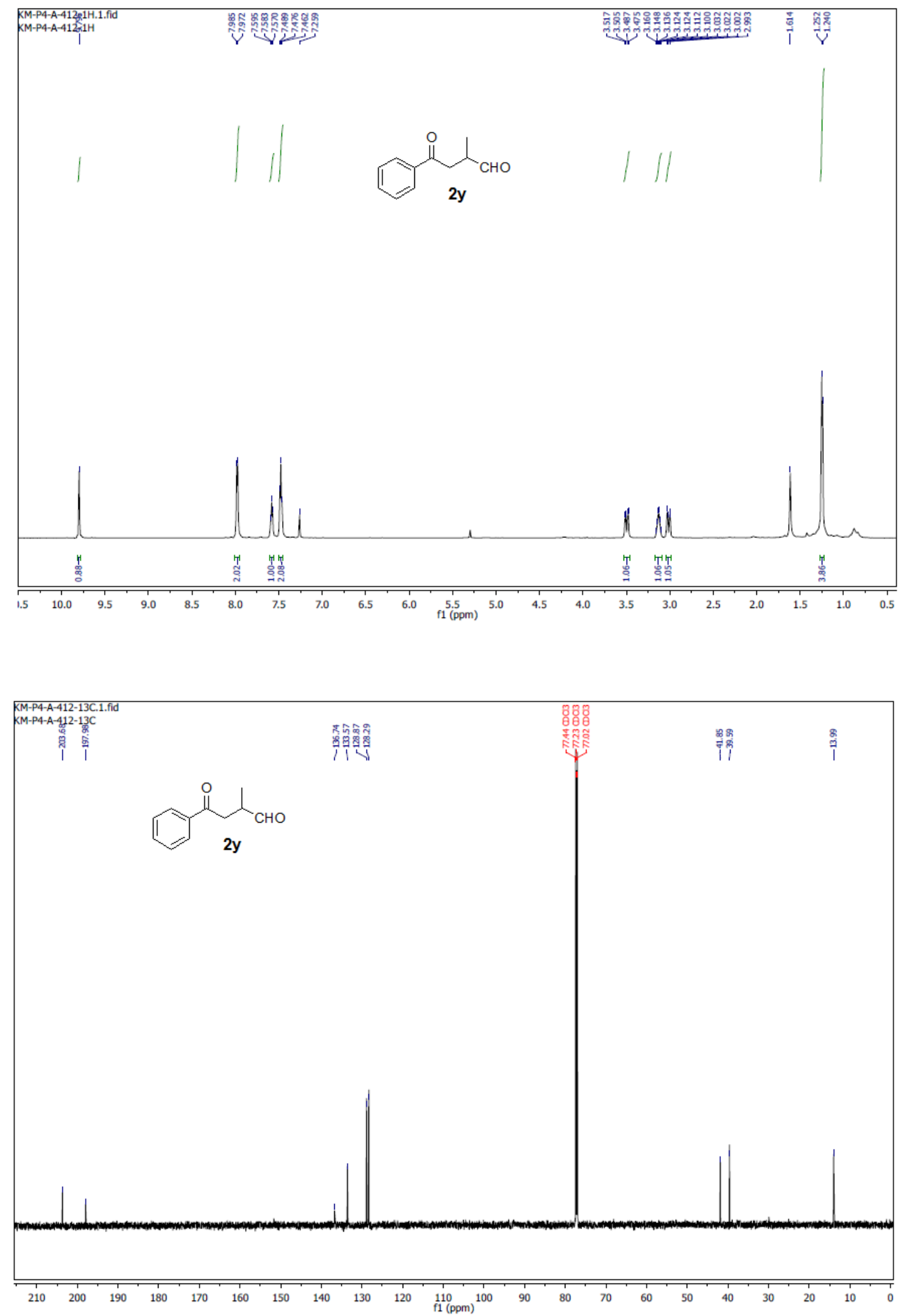


\section{$\underline{D}_{2} \underline{O}$ experiment spectra:}

${ }^{1} \mathrm{H}$ NMR of 2,3- $d_{2}$ product $(600 \mathrm{MHz})$ in $\mathrm{CDCl}_{3}$

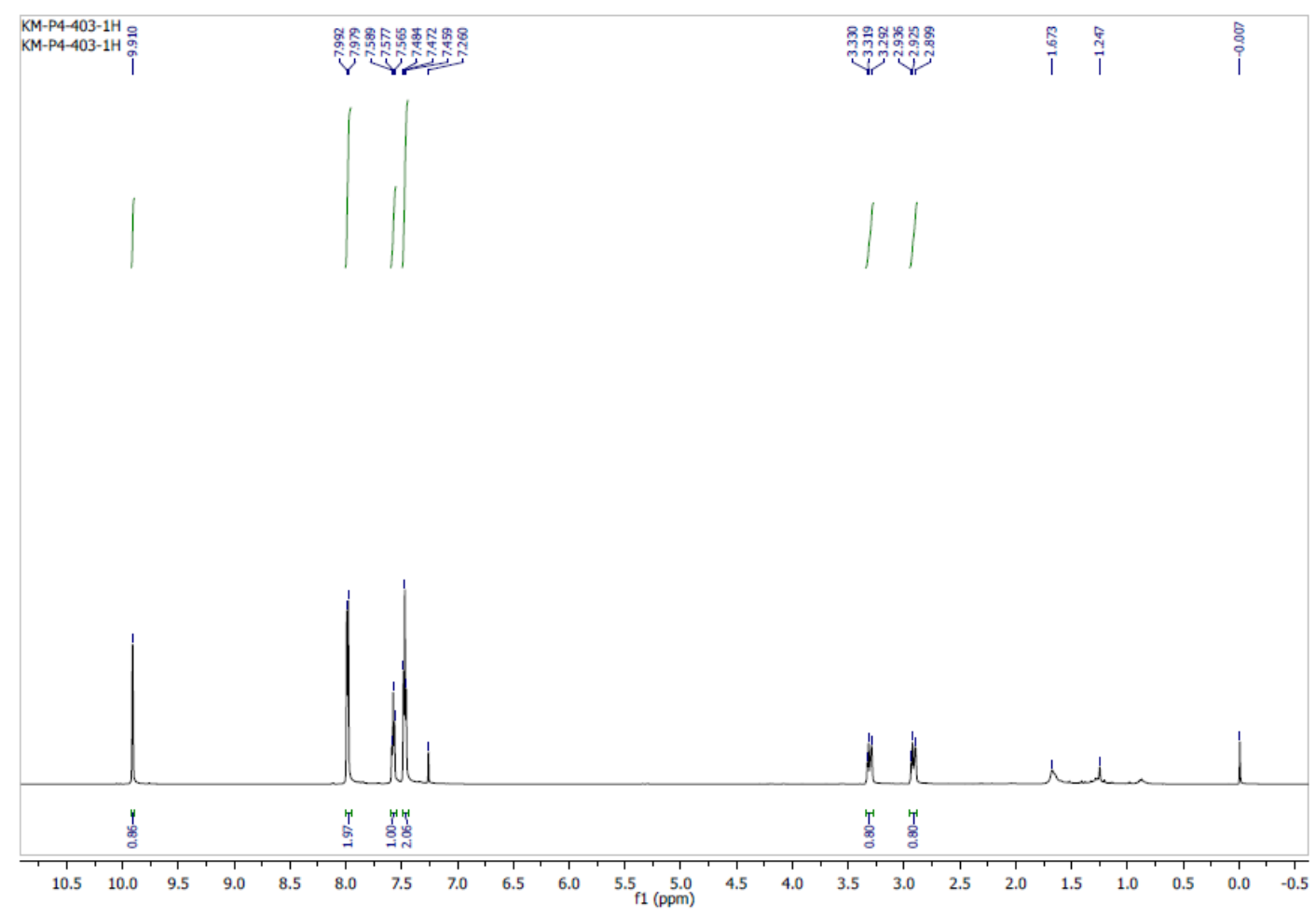

${ }^{13} \mathrm{C}$ NMR of 2,3- $d_{2}$ product $(600 \mathrm{MHz})$ in $\mathrm{CDCl}_{3}$

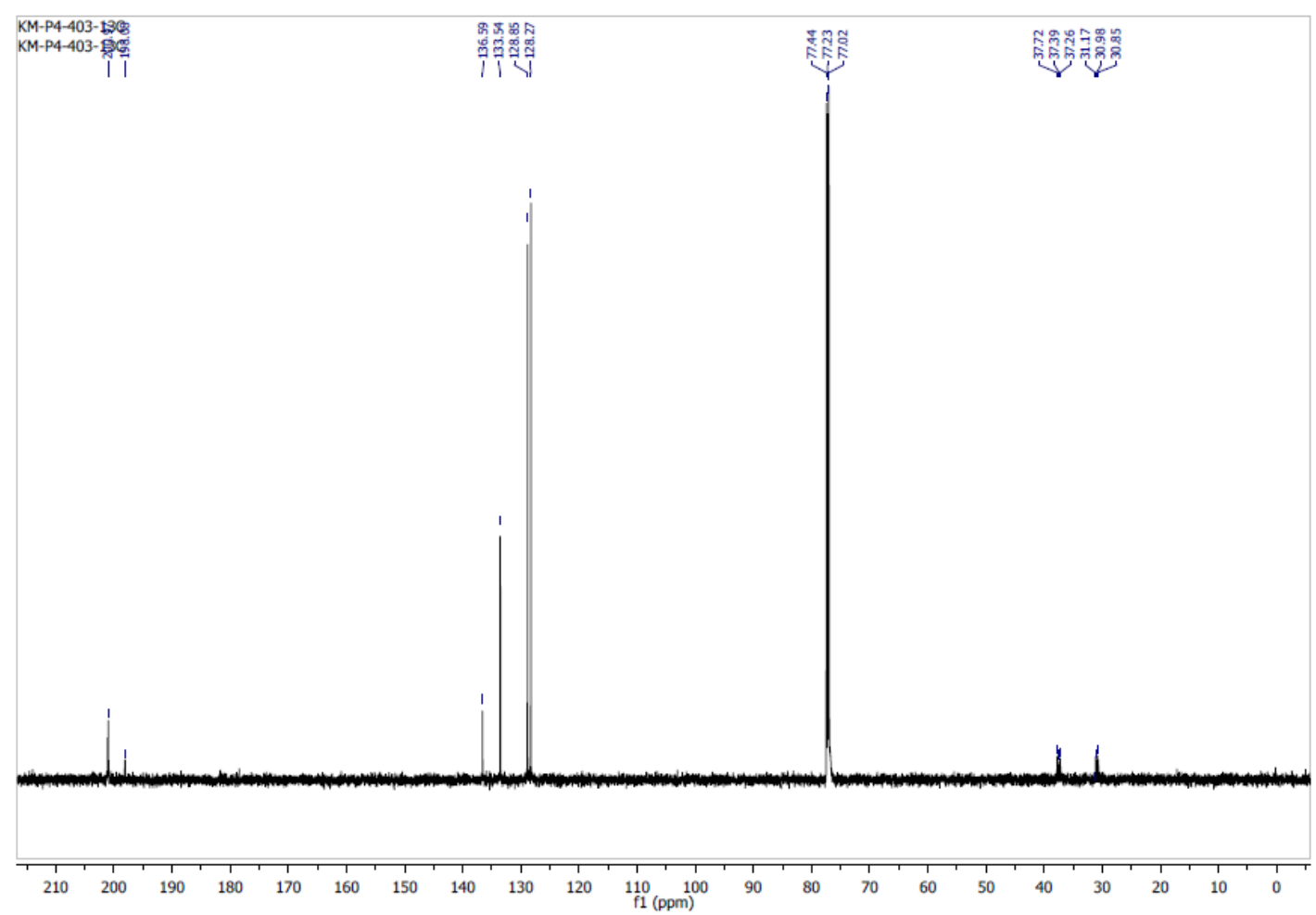

